\title{
Association of parents' alcohol use and family interaction with the initiation of alcohol use by sixth graders: A preliminary study in
} Taiwan

\author{
Chao-Chia Hung1,2, Lee-Lan Yen*2,3 and Wen-Chi Wu ${ }^{4}$
}

\begin{abstract}
Address: ${ }^{1}$ Department of Nursing, College of Health Sciences, Yuanpei University, 306 Yuanpei Street, Hsinchu 300, Taiwan, Republic of China, 2Institute of Health Policy and Management, College of Public Health, National Taiwan University, 17 Hsu-Chow Road, Taipei 100, Taiwan, Republic of China, ${ }^{3}$ Center for Health Policy Research and Development, National Health Research Institutes, 35 Keyan Road, Zhunan, Miaoli 350, Taiwan, Republic of China and ${ }^{4}$ Department of Public Health, College of Public Health, National Taiwan University, 17 Hsu-Chow Road, Taipei 100, Taiwan, Republic of China

Email: Chao-Chia Hung - d93845004@ntu.edu.tw; Lee-Lan Yen* - leelan@ntu.edu.tw; Wen-Chi Wu - wuvirsan@ms17.hinet.net

* Corresponding author
\end{abstract}

Published: 4 June 2009

BMC Public Health 2009, 9:172 doi:10.1 I86/147|-2458-9-172
Received: 19 August 2008

Accepted: 4 June 2009

This article is available from: http://www.biomedcentral.com/I47/-2458/9//72

(C) 2009 Hung et al; licensee BioMed Central Ltd.

This is an Open Access article distributed under the terms of the Creative Commons Attribution License (http://creativecommons.org/licenses/by/2.0), which permits unrestricted use, distribution, and reproduction in any medium, provided the original work is properly cited.

\begin{abstract}
Background: The family is the main environment where children are socialized and learn individual behavior. Although previous studies have examined predictors of preadolescent first alcohol use, few studies have analyzed factors associated with alcohol use in children in a country with low alcohol consumption. The aim of this study was to investigate the initiation of alcohol use by sixth graders and determine family factors associated with first alcohol use.

Methods: Data used in this study was collected as part of the Child and Adolescent Behaviors in Long-term Evolution (CABLE) project in 2002 (when study participants were in grade 5 and aged 10-II years) and 2003 (when study participants were in grade 6 and aged II-12 years). Data from a total of I, I83 participants was analyzed. Main study variables included children's alcohol use: (I) never user (never user in 2002 and 2003), or (2) first-time user (never user in 2002 but ever user in 2003); parents' alcohol use: (I) both parents ever users, (2) mother ever user and father never user, (3) father ever user and mother never user, (4) both parents never users; parental support; and family conflict. Correlates of first alcohol use were identified using logistic regression.
\end{abstract}

Results: There were 183 students (15.5\%) who became first-time users of alcohol in the sixth grade. Having parents who both used alcohol, less parental support, and more family conflict were significant predictors of sixth graders' first alcohol use. Family interaction and parents' drinking were equally important predictors of preteen's first use of alcohol.

Conclusion: Family factors influence children's initiation of alcohol use. It is important to educate parents about the effects of alcohol on children and to emphasize the importance of prevention.

\section{Background}

Underage drinking is a long standing major public health issue. According to the Global Status Report [1], in 23 countries in the European Union about half of school children have already tried alcohol by age 11 . Youth who start drinking early are at elevated risk of involvement in 
later alcohol and hard drug abuse [2,3]. Moreover, a number of studies have found that underage drinkers are at an increased risk of experiencing alcohol related unintentional or intentional injures compared to those who begin drinking at a later age [4-9]. The World Health Organization (WHO) $[1,10]$ has emphasized that the drop in age of onset of alcohol use by children and adolescents is an important issue for all nations and that effective strategies to delay the age of first alcohol use are needed. To date most research into factors associated with underage first use of alcohol has been carried out in countries with high alcohol consumption. Compared to Western countries alcohol consumption in Asian countries such as Taiwan is quite low $[11,12]$. However, as alcohol consumption among underage youth tends to increase along with rapid economic growth and lifestyle westernization [10], first alcohol use is an important issue in a low drinking society with high economic growth.

Although genetic factors contribute to the initiation of alcohol use $[13,14]$, the initiation of alcohol use in early adolescence is strongly influenced by social and familial environmental factors [15]. The social development model [16] incorporates social learning theory and social control theory in an integrated theoretical approach to identifying etiological and developmental mechanisms affecting behavior. Social learning theory [17] emphasizes the effect of modeling behavior. Young people who perceive more people drinking (e.g. parents or peers) are predicted to repeat this behavior in the future. Social control theory [18] emphasizes the predictive effect on behavior of social bonds to parents, school, peers and the community. Bonding is expected to serve a protective function against deviant behavior. The acceptance of alcohol consumption is a socialization behavior. As children are primarily socialized in the family, it is important to identify the familial factors associated with underage alcohol use.

Most studies have found parents' drinking and family interactions to be associated with adolescents' alcohol use. Greater alcohol use by parents is associated with earlier use of alcohol by adolescents [19-22] and children are more likely to use alcohol if both parents drink alcohol, as opposed to only one parent [23]. However, no consistent specific effects of either father's or mother's drinking alone on children's alcohol use have been found. Zhang et al. [24] found that father's drinking had a direct effect on adolescent alcohol use, but that mother's drinking did not. Most studies concerning the effect of parents' drinking on alcohol use either looked at mother's and father's alcohol use separately or did not provide a definition of parents' drinking. Few studies have investigated the impact of different match in problem alcohol use between parents. Moser \& Jacob [25] found that children with alcoholic parents were more likely to have problem behavior, regardless of whether alcoholism was present in the mother only, father only, or both parents. Further research is needed into the role of different combinations of parents' drinking on children's first use of alcohol.

Parenting behavior can also moderate child outcomes. One study found that children whose parents communicated more with them when they were in the sixth grade, and gave them more encouragement and physical affection in the seventh grade, were less likely to start using alcohol monthly when they reached the ninth grade [26]. In contrast, in families with more conflict, children and adolescents are more likely to use alcohol $[27,28]$. Hawkins et al [21] found that if parents participated in activities with their children often, communicated with their children often, and there was less family conflict, the onset of alcohol use by 11-18 year olds was delayed. These findings support a positive relationship between parental behavior and children's alcohol use and imply that certain parental behaviors may decrease the likelihood of children initiating alcohol use.

There is also evidence that the association between parents' drinking and children's alcohol use is mediated by family interaction variables. Moser \& Jacob [25] found that dual and mother-only alcoholic families had impaired interaction. El-Sheikh, \& Flanagan [29] confirmed that the association between parental problem drinking and children's externalizing problems was mediated by parent-child conflict. Latendresse et al [30] also demonstrated that parental monitoring and discipline are important mediators of the association between parental and adolescent alcohol use. Yu [31] found that parents' alcohol use did not have a direct effect on the time at which adolescents initiated alcohol use before the ages of 15-18. Rather, the shortened interaction time between children and parents was the reason behind the drop in age of onset of alcohol use. Parents' drinking may result in dysfunctional family relationships that constitute a noxious social environment for the children. Parents' alcohol use may have an effect on children's alcohol initiation through more family conflict or less parental support. Furthermore, White et al. [32] found that even after controlling for parents' proactive behavior, the effect of parents' alcohol use on children's alcohol use remained significant. This implies that both family interaction and parents' alcohol use are independently associated with children's first use of alcohol. Despite this volume of research, few studies to date have looked at the etiology of first alcohol use in elementary school children in a country with a low prevalence of drinking.

The overall aim of our study was to explore the effects of parents' alcohol use, parental support, and family conflict on the initiation of alcohol use in a sample of school chil- 
dren. We also examined whether the effect of parents' alcohol use and family interaction on children's initiation of alcohol were independent of each other.

\section{Methods}

\section{Participants}

Data for this study was obtained from the Child and Adolescent Behaviors in Long-term Evolution (CABLE) Project [33]. CABLE commenced in 2001 and is funded by the National Health Research Institutes in Taiwan. The CABLE student sample was established by randomly selecting nine schools each in Taipei City and Hsinchu County. Data were collected on the behaviors of school children in the first grade (cohort 1) and fourth grade (cohort 2) of these schools as well as their parents. After obtaining informed consent, children and their parents filled out separate self completed questionnaires. The two study cohorts were both followed up annually. The student questionnaires were completed by a whole class group at a time during a single lesson. For the parent questionnaires, students took the questionnaires home and asked their mothers and fathers to complete them separately. After completion, parents were asked to place the questionnaires in a sealed envelope, after which the children took them back to school and handed them in to a teacher.

In this study we analyzed data from the 2,499 students in cohort 2. In order to compensate for recall bias and to increase the accuracy of measurement of onset of alcohol use, we used school children's alcohol use data from 2002 (when students were $5^{\text {th }}$ graders and aged $10-11$ years) and 2003 (when students were $6^{\text {th }}$ graders and aged 11-12 years.). Participants with missing data were excluded. There were a total of 1,571 children with complete questionnaire data for themselves and both parents for 2002 and 2003 , which was $63 \%$ of the original sample. The chisquared test was used to assess differences between the final and original samples in regards to demographic variables (sex, residential area, parents' marital status, father's education level, mother's education level and household monthly income). Those not included in the final sample were more likely to have parents that were not married or not living together $\left(\chi^{2}=45.9, \mathrm{p}<0.01\right)$, and were more likely to have a mother with a low education level $\left(\chi^{2}=\right.$ $7.7, \mathrm{p}<0.05)$. There were no differences in terms of sex, residential area (Taipei city, and Hsinchu county), father's education level, and household monthly income. After excluding the 388 students who were already using alcohol in 2002, final analyses were carried out on the remaining 1,183 children who were never users in 2002.

\section{Measures}

Data on children's use of alcohol was taken from the 2002 and 2003 self completed student questionnaires. Data on parental support, family conflict, sex, and residential area were also taken from the 2002 self completed student questionnaires. The remaining data was obtained from the 2002 parent self completed questionnaires.

\section{Alcohol use by school children}

Donovan [34] has suggested that in the measurement of initiation of alcohol use, first alcohol use should be considered as the first time alcohol is consumed by an individual who has previously never used alcohol (lifetime abstainer). We have used this suggested standard to define first alcohol use in our study. Use of alcohol was assessed by the question "Have you ever used alcohol?", and was scored using a Likert scale which in the 2002 questionnaire included the responses: 1 . Never; 2 . Yes, but not in the past month; 3 . Once or twice in the past month; 4 . Many times in the past month; or 5 . Every day in the past month. In the 2003 questionnaire response options were: 1. Never; 2 . Yes, but not in the past year; 3 . Yes, but not in the past month; 4 . Once or twice in the past month; 5 . Many times in the past month; or 6 . Every day in the past month. For both years, we divided the children into two groups based on their above responses: 1 . Never-user; or 2. Ever-user. Changes in status between 2002 and 2003 were then used to divide the children into three alcohol use groups: Never-user (never-user in 2002 and 2003); First-time user (never-user in 2002 but ever-user in 2003); and Ever-user (ever-user in 2002 and 2003). Finally, we excluded those students who were ever-users initially before investigating influential factors on first alcohol use.

\section{Parent's alcohol use}

Assessment of parent's alcohol use in the 2002 parent's questionnaire included the responses: 1 . Never; 2 . Yes, but not in the past month; 3 . Once or twice in the past month; 4. Many times in the past month; or 5. Every day in the past month. We grouped responses 1 and 2 as never-users and responses 3, 4 and 5 as ever-users. Then based on the matching of alcohol use between both parents, a dummy variable including the following four groups was created: both parents ever-users; mother ever-user and father never-user; father ever-user and mother never-user; and both parents never-users. The reference group was both parents never-users.

\section{Family interaction factors}

This included both parental support and family conflict. Parental support was measured by seven items, "Do your parents encourage you when you face difficulties", "Do your parents praise you for your achievements", "Do your parents console you when you are upset", "Do your parents care for you when you are sick", "Do your parents listen to what you say", "Do your parents care about what happens at school", "Do your parents help you solve problems". The internal consistency (Cronbach's alpha) 
for the study sample was 0.88 . Family conflict was measured by the five items: "mum and dad argue", "mum and dad physically fight", "my brothers and sisters argue", "my brothers and sisters physically fight", "I argue with mum and dad or other family members". The Cronbach's alpha value for our sample was 0.60 . All of the above items were scored from one (never) to four (every day). Higher mean scores on each measure indicated more parental support and more conflict. Factor analysis revealed the $\mathrm{R}^{2}$ for these two variables was $58.57 \%$ in parental support and $39.30 \%$ in family conflict.

\section{Background factors}

This included seven demographic dummy variables. Factors associated with alcohol use in past research [35-37] include sex, residential area, parents' marital status, and family socioeconomic status. Therefore relevant variables included in this study were: sex (female as the reference group), residential area (Taipei city and Hsinchu county; Taipei city as the reference group), parents' marital status (married and living together and other; other as the reference group), household monthly income $(<40000$, 40000-100000, >100000; >100000 as the reference group), father's education level (middle school and below, high school, university or research institute; university or research institute as the reference group), and mother's education level (middle school and below, high school, university or research institute; university or research institute as the reference group).

\section{Ethics}

Ethics approval was given in 2001 by the Human Ethics Committee at National Health Research Institutes, Miaoli, Taiwan.

\section{Data analysis}

Data analysis was carried out using SPSS 12.0 statistical software. Descriptive statistical analysis included mean values, percentages and frequency distributions. The dependent variable was alcohol use group and the independent variables were background factors, parent's alcohol use, parental support and family conflict. Bivariate analysis was used to examine the correlations between each variable and alcohol use group. Stepwise logistic regression was then used to assess the relationship between independent variables and first alcohol use in school children.

Two separate regression models were built. In the first step of the analysis, we entered background variables and parents' alcohol use factors into model 1 to test the effect of parents' alcohol use on children's first alcohol use. In the second step, we constructed the full model that included all independent variables to explore the effect of parental support and family conflict on the children's first alcohol use. This allowed us to examine the changes in significance of parents' alcohol use after the addition of these two family interaction factors.

\section{Results}

\section{Alcohol use and predictors in the study sample}

There were 1,000 students $(84.5 \%)$ who were never-users of alcohol in both grade 5 and grade 6 and 183 students $(15.5 \%)$ who were never-users in grade 5 but became firsttime users in grade 6 .

The distribution of predictors in the study sample in each of the alcohol use subgroups are shown in Table 1 . In general, 46.1\% were boys and 53.9\% were girls; and 54\% lived in a metropolitan area (Taipei city). In regards to the parents, $93.7 \%$ of parents were married and living together; $55.5 \%$ had monthly household incomes of NT $\$ 40,000$ to NT\$100,000. The majority of parents had a high school level of education (57\% of fathers and $66.3 \%$ of mothers). Parents who were both never-users of alcohol constituted $44.4 \%$ of the sample. First-time alcohol users were more likely to have a lower mean score for parental support $(22.1 \pm 4.9$ vs $20.8 \pm 5.3, \mathrm{t}=3.36, \mathrm{p}<$ $0.01)$, and to have a higher mean score for family conflict $(8.8 \pm 1.9$ vs $9.2 \pm 2.1, \mathrm{t}=-2.63, \mathrm{p}<0.01)$.

Table 2 presents the correlation matrix for the variables. Of note is that alcohol use group was significantly positively correlated with household income, parents' alcohol use, and family conflict but significantly negatively correlated with parental support. In addition, family conflict was significantly negatively correlated with parental support $(r=-0.20)$. However, parents' alcohol use was not significantly associated with family interaction factors, either parental support or family conflict.

\section{Factors related to first-time alcohol use in sixth grade children}

Logistic regression was used to determine factors associated with first-time alcohol use in sixth graders. The results are shown in Table 3 . Model 1 revealed that without considering parental support and family conflict, parents' alcohol use increased the odds of children's initiation of alcohol use. Alcohol use by both parents was significantly associated with first time alcohol use by sixth grade students (OR:1.62, 95\%CI = 1.01-2.59). A non-significant relationship was found between having only one parent who was an ever-user (father or mother) and first use of alcohol in the sixth grade. Model 2 showed that after adjusting for parents' alcohol use, children with less perceived parental support (OR: 0.95, 95\%CI $=0.92-$ 0.99 ) and more family conflict (OR: $1.11,95 \% \mathrm{CI}=1.02-$ 1.20) were more likely to become first-time users of alcohol. Moreover, after adjusting for family interaction factors, the effect of parents' alcohol use on children's first 
Table I: Predictors of alcohol use in the study sample

\begin{tabular}{|c|c|c|c|c|c|c|c|}
\hline \multirow[b]{2}{*}{ Variable } & \multicolumn{2}{|c|}{ Total } & \multicolumn{5}{|c|}{ Alcohol use group } \\
\hline & \multicolumn{2}{|c|}{$\begin{array}{c}(\mathrm{n}=1183) \\
n \% \\
\text { mean } \pm S D\end{array}$} & \multicolumn{2}{|c|}{$\begin{array}{c}\text { Never-user }(n=1000) \\
n \% \\
\text { mean } \pm S D\end{array}$} & \multicolumn{2}{|c|}{$\begin{array}{c}\text { First-time user }(n=183) \\
n \% \\
\text { mean } \pm \text { SD }\end{array}$} & \\
\hline & & & & & & & $\chi^{2}-2.45$ \\
\hline Male & 545 & 46.1 & 451 & 45.1 & 94 & 51.4 & \\
\hline Female & 638 & 53.9 & 549 & 54.9 & 89 & 48.6 & \\
\hline Residential area & & & & & & & $\chi^{2}=0.12$ \\
\hline Taipei & 639 & 54.0 & 538 & 53.8 & 101 & 55.2 & \\
\hline Hsinchu & 544 & 46.0 & 462 & 46.2 & 82 & 44.8 & \\
\hline Parents' marital status/living arrangements & & & & & & & $\chi^{2}=0.34$ \\
\hline Married and live together & 1109 & 93.7 & 938 & 93.8 & 171 & 93.4 & \\
\hline Other & 74 & 6.3 & 62 & 6.2 & 12 & 6.6 & \\
\hline \multicolumn{8}{|l|}{ Household monthly income (NTD) } \\
\hline$<40000$ & 173 & 14.6 & 156 & 15.6 & 17 & 9.3 & $\chi^{2}=5.23$ \\
\hline $40000-100000$ & 657 & 55.5 & 552 & 55.2 & 105 & 57.4 & \\
\hline$>100000$ & 353 & 29.8 & 292 & 29.2 & 61 & 33.3 & \\
\hline Father's education level & & & & & & & $\chi^{2}=5.80$ \\
\hline Middle school and below & 156 & 13.2 & 142 & 14.2 & 14 & 7.7 & \\
\hline High school & 674 & 57.0 & 563 & 56.3 & 111 & 60.7 & \\
\hline University or research institute & 353 & 29.8 & 295 & 29.5 & 58 & 31.7 & \\
\hline Mother's education level & & & & & & & $\chi^{2}=1.72$ \\
\hline Middle school and below & 165 & 13.9 & 138 & 13.8 & 27 & 14.8 & \\
\hline High school & 784 & 66.3 & 670 & 67.0 & 114 & 62.3 & \\
\hline University or research institute & 234 & 19.8 & 192 & 19.2 & 42 & 23.0 & \\
\hline Parents' matched alcohol use group & & & & & & & $\chi^{2}=5.56$ \\
\hline Both parents ever-users & 167 & 14.1 & 135 & 13.5 & 32 & 17.5 & \\
\hline Mother ever-user, father never-user & 60 & 5.1 & 48 & 4.8 & 12 & 6.6 & \\
\hline Father ever-user, mother never-user & 431 & 36.4 & 360 & 36.0 & 71 & 38.8 & \\
\hline Both parents never-users & 525 & 44.4 & 457 & 45.7 & 68 & 37.2 & \\
\hline Parental support (score 7-28) & $21.9 \pm 5.0$ & & $22.1 \pm 4.9$ & & $20.8 \pm 5.3$ & & $t=3.36$ \\
\hline Family conflict (score 5-20) & $8.8 \pm 2.0$ & & $8.8 \pm 1.9$ & & $9.2 \pm 2.1$ & & $t=-2.63$ \\
\hline
\end{tabular}

$* * p<.01$

Never-user defined as never used alcohol in 2002 and 2003, first-time user defined as never used alcohol in 2002 but ever used alcohol in 2003

use of alcohol remained significant (OR:1.64, 95\%CI = 1.02-2.64).

These findings suggest that parents' alcohol use, family conflict and parental support all play important roles in the risk of initiation of alcohol use by children.

\section{Discussion}

The earlier that young people start drinking, the more likely they are to misuse alcohol and to experience alcohol dependence and alcohol-related unintentional injuries later in life $[2,38,39]$. Our results highlight the role of parents' alcohol use and family interaction in the progression from abstention to first alcohol use in sixth grade children. Past researchers $[7,12,19,22,26]$ have examined the factors related to the initiation of alcohol use. In our study we have followed the definition of Donovan [34], which more strictly defines first alcohol use and is more suitable for school children in countries with a low rate of alcohol use. After excluding those children who had already used alcohol, our study found that $15.5 \%$ of children became first-time users in the sixth grade. As the Children and Youth Welfare Law [40] prohibits any consumption of alcohol by children, any increase in the proportion of children with first alcohol use in the sixth grade warrants attention.

The family is a child's first social environment and provides the child with a background for behavioral development of both risky and healthy behaviors. Although other research [32,41] has found that father's alcohol use and mother's alcohol use have different influential effects on adolescents' drinking behavior, our results did not find any individual effects of father's or mother's alcohol use. The likelihood of children initiating alcohol use was only increased when both parents were using alcohol. In contrast to other studies, our data was obtained from parents' self reports, and therefore is more able to clarify the influ- 
Table 2: Correlation matrices for variables

\begin{tabular}{|c|c|c|c|c|c|c|c|c|c|c|}
\hline variable & I & 2 & 3 & 4 & 5 & 6 & 7 & 8 & 9 & 10 \\
\hline I. Sex ${ }^{a}$ & 1 & & & & & & & & & \\
\hline 2. Areab & -0.03 & I & & & & & & & & \\
\hline 3. Parent's marital status ${ }^{c}$ & 0.00 & $-0.06^{*}$ & I & & & & & & & \\
\hline 4. Household incomed & $0.06 *$ & $-0.30 * * *$ & $0.08^{* *}$ & I & & & & & & \\
\hline 5. Father's education levele & 0.04 & $-0.31 * * *$ & $0.09 * *$ & $0.46 * * *$ & 1 & & & & & \\
\hline 6. Mother's education levelf & 0.02 & $-0.30 * * *$ & $0.07^{*}$ & $0.46 * * *$ & $0.57^{* * *}$ & I & & & & \\
\hline 7. Parents' matched alcohol use groupg & 0.04 & $0.08 * *$ & -0.01 & -0.03 & $-0.06^{*}$ & -0.04 & I & & & \\
\hline 8. Parental support & $-0.13^{* * *}$ & $-0.08 * *$ & 0.03 & $0.08 * *$ & $0.12^{* * * *}$ & $0.10 * * *$ & -0.05 & 1 & & \\
\hline 9. Family conflict & -0.03 & $0.12^{* * *}$ & -0.00 & $-0.08 * *$ & -0.04 & -0.05 & 0.02 & $-0.20 * * *$ & I & \\
\hline 10. Alcohol use grouph & 0.05 & -0.01 & -0.01 & $0.06^{*}$ & 0.05 & 0.02 & $0.06^{*}$ & $-0.10^{* *}$ & $0.08^{* *}$ & I \\
\hline
\end{tabular}

$*_{\mathrm{p}}<.05 ; * * \mathrm{p}<.01 ; * * * \mathrm{p}<.001$

aSex $0=$ Female; $I=$ Male

bArea $0=$ Taipei; $\mathrm{I}=$ Hsinchu

cParent's marital status $0=$ other; $I=$ married and live together

dHousehold income(NTD) I =< 40000; 2 = 40000-100000; 3 => 100000

eFather's education level I = Middle school and below; 2 = High school; $3=$ University or research institute

fMother's education level I = Middle school and below; 2 = High school; 3 = University or research institute

gParents' matched alcohol use group I = Both parents never-users; 2 = Mother ever-user, father never-user; 3 = Father ever-user, mother never-

user; 4 = Both parents ever-users

hAlcohol use group $0=$ Never-user; I = First-time user

ence of parents' alcohol use on school children's initiation of alcohol use. Our findings agree with those of Li et al. [23], who found that children's alcohol use was influenced by the number of parents using alcohol. According to the social development model [16], the behavior of an individual will be prosocial or antisocial depending on the predominant behaviors, norms, and values held by those individuals or institutions to which the individual is bonded. It is possible that having both parents use alcohol provides children with more opportunities for observation and reinforcement of this behavior [17], such as the imitation of their parents' drinking behavior, internalization of their parents' attitudes of support for alcohol use, and positive expectations of the effects of alcohol $[16,28,42]$.

Table 3: Factors associated with first alcohol use in the study sample $(n=|| 83)$

\begin{tabular}{|c|c|c|c|c|c|c|}
\hline \multirow[b]{2}{*}{ Variable } & \multicolumn{3}{|c|}{ Model I } & \multicolumn{3}{|c|}{ Model 2} \\
\hline & $\beta$ & OR & $95 \% \mathrm{Cl}$ & $\beta$ & OR & $95 \% \mathrm{Cl}$ \\
\hline Sex: male/female & 0.19 & 1.20 & $0.88-1.66$ & 0.13 & 1.14 & $0.82-1.59$ \\
\hline Area: Hsinchu/Taipei & 0.02 & 1.03 & $0.72-1.46$ & -0.05 & 0.96 & $0.67-1.37$ \\
\hline Parent's marital status/living arrangements: Married and living together/other & -0.17 & 0.84 & $0.44-1.62$ & -0.18 & 0.83 & $0.43-1.61$ \\
\hline \multicolumn{7}{|l|}{ Household income (NT\$/month): } \\
\hline$<40,000 />100,000$ & -0.59 & 0.55 & $0.29-1.07$ & $-0.68^{*}$ & 0.51 & $0.26-0.98$ \\
\hline $40,000-100,000 />100,000$ & -0.10 & 0.91 & $0.61-1.36$ & -0.12 & 0.89 & $0.59-1.33$ \\
\hline \multicolumn{7}{|l|}{ Father's education level } \\
\hline Middle school and below/university or research institute & -0.62 & 0.54 & $0.26-1.12$ & -0.70 & 0.50 & $0.24-1.05$ \\
\hline High school/university or research institute & 0.11 & 1.11 & $0.71-1.75$ & 0.12 & 1.12 & $0.71-1.78$ \\
\hline \multicolumn{7}{|l|}{ Mother's education level } \\
\hline Middle school and below/university or research institute & 0.27 & 1.32 & $0.67-2.59$ & 0.27 & 1.31 & $0.66-2.61$ \\
\hline High school/university or research institute & -0.23 & 0.80 & $0.49-1.30$ & -0.27 & 0.77 & $0.47-1.25$ \\
\hline \multicolumn{7}{|l|}{ Parents' matched alcohol use group } \\
\hline Both parents ever-users/both never-users & $0.48^{*}$ & 1.62 & $1.01-2.59$ & $0.50 *$ & 1.64 & $1.02-2.64$ \\
\hline Mother ever-user, father never-user/both never-users & 0.50 & 1.65 & $0.83-3.27$ & 0.46 & 1.58 & $0.79-3.18$ \\
\hline Father ever-user, mother never-user/both never-users & 0.25 & 1.28 & $0.89-1.85$ & 0.21 & 1.24 & $0.86-1.79$ \\
\hline Parental support (score 7-28) & & & & $-0.05^{* *}$ & 0.95 & $0.92-0.99$ \\
\hline Family conflict (score $5-20$ ) & & & & $0.10 *$ & 1.11 & $1.02-1.20$ \\
\hline
\end{tabular}

$*_{\mathrm{p}}<.05 ; *_{\mathrm{p}}<.01$ 
Cultural differences might be another explanation for the differences that we have observed. American and European culture is more individualistic as opposed to Chinese culture, which is more collectivistic than European, African, American, and other Asian cultures [43]. Collectivist societies emphasize the social unit with a common fate. Common values are centralized rather than promoting personal uniqueness and focusing on the individual as in individualistic societies. Family is the primary society for the individual, and having a father and mother who both drink may send a stronger impression of the social context of acceptable drinking behavior to children than the effect of only one parent drinking. Warner and White [8] found that many children and adolescents first use alcohol at family gatherings. Having a father and mother who both use alcohol may increase children's contact with alcoholic drinks and their opportunities to taste alcohol at family gatherings.

After controlling for parental support and family conflict, parent's alcohol use still had a significant effect on sixth graders' first alcohol use. This result agrees with the findings of previous research [19-21]. We did not find a relationship between parents' drinking and family interaction, either parental support or family conflict. Parents' drinking in this study was not defined according to quantity or the presence of a drinking problem as in previous studies [25]. It is possible that the association of parents' drinking with parental support and family conflict occur only with heavier alcohol use by parents. Our results are similar to the position of White et al [32] who found that the family factors of father's and mother's alcohol use, and parental warmth or hostility had independent effects on children sustaining alcohol use from adolescence into adulthood. It is implied that both family interaction and parents' drinking are equally important in preteen's first use of alcohol.

Our results agree with those of other researchers $[21,22,26]$ who have found that parental emotional support is an important protective factor against the initiation of alcohol use by adolescents and that children whose parents communicate with them more often are less likely to begin using alcohol in adolescence. The measurement instrument for family support in our study incorporated parental listening and care which may reflect the amount of time parents spend communicating with their children. Research $[44,45]$ indicates that frequent communication and involvement between parents and children can increase adolescents' ability to say no to alcohol in a variety of situations and as a result decreases the influence of friends with unhealthy behavior and decreases substance use behavior. Our finding that family conflict can predict alcohol initiation in sixth grade children also agrees with previous research $[27,28]$. Social bonds to conventional society inhibit association with delinquent peers and, in turn, prevent delinquent behavior [16]. Children who experience more family conflict are more likely to use alcohol because their parents show less concern about their whereabouts or because they lack social skills for coping with stress. This enables these children to both congregate with other peers that have unhealthy behaviors and carry out unhealthy behavior themselves $[27,28]$.

For the most part, our findings replicate those from the United States. This could be due to the high level of westernization of the Taiwanese study population, or alternatively it could be due to common social psychological processes that transcend cultural differences in causing or buffering against alcohol use among preteens.

Decreasing the proportion of children and adolescents using alcohol and delaying the age of onset of alcohol use are important goals for alcohol use policy [1,10]. Our study makes three major contributions to this field of research. Firstly, our study subjects were a number of elementary school students whose alcohol use behavior was followed over two years. This enabled the confirmation of a group of children who changed from being an abstainer to a first-time user, and allowed us to examine risk factors for sixth graders' first use of alcohol. Secondly, having parents who were both alcohol users significantly increased the likelihood of school children initiating alcohol use. It is possible that having a proactive family relationship could decrease the likelihood of initiation of alcohol use by school children. Based on our findings, we recommend the strengthening of prevention efforts targeting parents, focusing on educating them about the effects of alcohol use on children and about proactive family management practice. Finally, our study furthers understanding of underage alcohol use in a low alcohol consumption society, and similar research might be replicated in other low alcohol use countries.

Limitations of our study include changes to how alcohol use was measured over the two years. This meant that we were only able to explain factors predicting school children's first alcohol use in the sixth grade. Future research should conduct longer follow up in order to increase the understanding of factors influencing alcohol use behavior in children. Secondly, due to data limitations we were unable to investigate the amount of alcohol consumed by parents or children or the type of alcohol consumed. However, as the legal age for drinking in Taiwan is 18 years, and our study was mainly concerned with factors influencing initiation of alcohol use amongst school children, we feel that this is not a major concern. Finally, even though family conflict was significantly associated with preteen's first alcohol use, it is important to note that the 
Cronbach's alpha coefficient for family conflict was quite low.

\section{Conclusion}

In conclusion, parent's alcohol use, parental support and family conflict had an influential effect on the initiation of alcohol use by sixth grade children. We recommend the strengthening of prevention efforts targeting parents' family management practices and emphasizing the unfavorable effect of parents' alcohol use on preteen early use of alcohol.

\section{Competing interests}

The authors declare that they have no competing interests.

\section{Authors' contributions}

$\mathrm{CCH}$ designed the study, carried out statistical data analysis, interpreted the data, and prepared the manuscript; LLY contributed to design development, data interpretation, and provided data analysis advice; WCW helped to perform the statistical analysis as well as to prepare the draft of the manuscript. All authors read and approved the final manuscript.

\section{Acknowledgements}

This research had been supported partially by a grant from the College of Public Health, National Taiwan University - Enhancing Capabilities for Social and Behavioral Sciences Research. We would also like to thank the National Health Research Institutes funded Child and Adolescent Behaviors in Long-term Evolution (CABLE) project for providing data for this study.

\section{References}

I. WHO: Global status report: alcohol and young people $200 \mathrm{I}$. [http://whqlibdoc.who.int/hq/200I/WHO MSD MSB 0l.l.pdf].

2. King KM, Chassin L: A prospective study of the effects of age of initiation of alcohol and drug use on young adult substance dependence. J Stud Alcohol Drugs 2007, 68:256-265.

3. Agrawal A, Grant JD, Waldron M, Duncan AE, Scherrer JF, Lynskey MT, Madden PA, Bucholz KK, Heath AC: Risk for initiation of substance use as a function of age of onset of cigarette, alcohol and cannabis use: findings in a Midwestern female twin cohort. Prev Med 2006, 43: I25-I28.

4. Kandel D: Stages in adolescent involvement in drug use. Science 1975, 190:912-9|4.

5. Kandel D, Yamaguchi K: From beer to crack: Developmental patterns of drug involvement. Am J Public Health 1993, 83:85I-855.

6. Yen LL, Chiu CJ, Wu WC, Pan LY: Aggregation of health behaviors among fourth graders in northern Taiwan. J Adolesc Health 2006, 39:435-442.

7. Wilson N, Battistich V, Syme SL, Boyce WT: Does elementary school alcohol, tobacco, and marijuana use increase middle school risk. J Adolesc Health 2002, 30:442-447.

8. Warner LA, White HR: Longitudinal effects of age at onset and first drinking situations on problem drinking. Subst Use Misuse 2003, 38:1983-2016.

9. Swahn MH, Bossarte RM, Sullivent EE: Age of alcohol use initiation, suicidal behavior, and peer and dating violence victimization and perpetration among high-risk, seventh-grade adolescents. Pediatrics 2008, 121:297-305.

10. WHO: Global status report on alcohol 2004. [http:// www.who.int/substance abuse/publications/ global status report 2004 overview.pdf].
II. Yang MJ: The Chinese Drinking Problem: A Review of the Literature and Its Implication in a Cross-Cultural Study. The Kaohsiung Journal of Medical Sciences 2002, I 8:543-550.

12. Kosterman R, Hawkins JD, Guo J, Catalano RF, Abbott RD: The dynamics of alcohol and marijuana initiation: patterns and predictors of first use in adolescence. Am J Public Health 2000, 90:360-366.

13. Schlaepfer IR, Hoft NR, Collins AC, Corley RP, Hewitt JK, Hopfer CJ, Lessem JM, McQueen MB, Rhee SH, Ehringer MA: The CHRNA5I A3/B4 gene cluster variability as an important determinant of early alcohol and tobacco initiation in young adults. Biol Psychiatry 2008, 63:1039-1046.

14. Poelen EA, Derks EM, Engels RC, van Leeuwe JF, Scholte RH, Willemsen $\mathrm{G}$, Boomsma DI: The relative contribution of genes and environment to alcohol use in early adolescents: are similar factors related to initiation of alcohol use and frequency of drinking? Alcohol Clin Exp Res 2008, 32:975-982.

15. Kendler KS, Schmitt E, Aggen SH, Prescott CA: Genetic and environmental influences on alcohol, caffeine, cannabis, and nicotine use from early adolescence to middle adulthood. Arch Gen Psychiatry 2008, 65:674-682.

16. Hawkins JD, Weis JG: The social development model: An integrated approach to delinquency prevention. J Prim Prev 1985, 6:73-97.

17. Bandura A: Social foundations of thought and action: $A$ social cognitive theory. Englewood Cliffs, New Jersey, Prentice-Hall; 1986.

18. Hirschi T: Causes of Delinquency. In Causes of Delinquency Berkely: University of California Press; 1969.

19. Jackson C: Initial and experimental stages of tobacco and alcohol use during late childhood: Relation to peer, parent, and personal risk factors. Addict Behav 1997, 22:685-698.

20. Ellickson PL, Hays RD: Antecedents of drinking among young adolescents with different alcohol use histories. J stud alcohol 1991, 52:398-408.

21. Hawkins JD, Graham JW, Maguin E, Abbott R, Hill KG, Catalano RF: Exploring the effects of age of alcohol use initiation and psychosocial risk factors on subsequent alcohol misuse. J stud alcohol 1997, 58:280-290.

22. Garmiene A, Zemaitiene N, Zaborskis A: Family time, parental behaviour model and the initiation of smoking and alcohol use by ten-year-old children: an epidemiological study in Kaunas, Lithuania. BMC Public Health 2006, 6:287-295.

23. Li C, Pentz MA, Cho CP: Parental substance use as a modifier of adolescent substance use risk. Addiction 2002, 97: I537-I550.

24. Zhang L, Welte JW, Wieczorek WF: The influence of parental drinking and closeness on adolescent drinking. J stud alcohol 1999, 60:245-25I.

25. Moser RP, Jacob T: Parent-child interactions and child outcomes as related to gender of alcoholic parent. J Subst Abuse 1997, 9: 189-208.

26. Cohen DA, Richardson J, LaBree L: Parenting behaviors and the onset of smoking and alcohol use: A longitudinal study. Pediatrics 1994, 94:369-373.

27. Webb JA, Baer PE: Influence of family disharmony and parental alcohol use on adolescent social skills, self-efficacy, and alcohol use. Addict Behav 1995, 20:127-135.

28. Ary DV, Duncan TE, Duncan SC, Hopes H: Adolescent problem behavior: the influence of parents and peers. Behav Res Ther 1999, 37:217-230.

29. El-Sheikh M, Flanagan E: Parental problem drinking and children's adjustment: family conflict and parental depression as mediators and moderators of risk. J Abnorm Child Psycho 200I, 29:417-432.

30. Latendresse SJ, Rose RJ, Viken RJ, Pulkkinen L, Kaprio J, Dick DM: Parenting mechanisms in links between parents' and adolescents' alcohol use behaviors. Alcohol Clin Exp Res 2008, 32:322-330.

31. Yu J: The association between parental alcohol-related behaviors and children's drinking. Drug Alcohol Depend 2003, 69:253-262.

32. White HR, Johnson V, Buyske S: Parental modeling and parenting behavior effects on offspring alcohol and cigarette use:A growth curve analysis. J Subst Abuse 2000, 12:287-310. 
33. Yen LL, Chen L, Lee SH, Hsiao CH, Pan LY: Child and adolescent behavior in long-term evolution (CABLE): a school-based health lifestyle study. Promot Educ 2002:33-40.

34. Donovan JE: Adolescent alcohol initiation: A review of psychosocial risk factors. J Adolesc Health 2004, 35:529e7-529el8.

35. Denton $M$, Walters $V$ : Gender differences in structural and behavioral determinants of health: an analysis of the social production of health. Soc Sci Med 1999, 48: I 22 I-I 235.

36. Eaton DK, Forthofer MS, Zapata LB, Brown KR, Bryant CA, Reynolds ST, McDermott RJ: Factors related to alcohol use among $6^{\text {th }}$ through $10^{\text {th }}$ graders: the Sarasota county demonstration project. I Sch Health 2004, 74:95-104.

37. Richter M, Leppin A, Nic Gabhainn S: The relationship between parental socio-economic status and episodes of drunkenness among adolescents: findings from a cross-national survey. BMC Public Health 2006, 6:289-297.

38. White HR, Jarrett N, Valencia EY, Loeber R, Wei E: Stages and sequences of initiation and regular substance use in a longitudinal cohort of black and white male adolescents. J Stud Alcohol Drugs 2007, 68:173-181.

39. Eaton DK, Kann L, Kinchen S, Ross J, Hawkins J, Harris WA, Lowry $\mathrm{R}$, McManus T, Chyen D, Shanklin S, et al.: Youth risk behavior surveillance - United States, 2005. J Sch Health 2006, 76:353-372.

40. Children Bureau Ministry of Interior Republic of China: Children And Youth Welfare law [http://www.cbi.gov.tw/CBI 2/ internet/english/index.aspx]

4I. Yeh MY: Factors associated with alcohol consumption, problem drinking, and related consequences among high school students in Taiwan. Psychiatry Clin Neurosci 2006, 60:46-54.

42. Callas PW, Flynn BS, Worden JK: Potentially modifiable psychosocial factors associated with alcohol use during early adolescence. Addict Behav 2004, 29: I503-I5I5.

43. Oyserman D, Coon HM, Kemmelmeier M: Rethinking individualism and collectivism: evaluation of theoretical assumptions and meta-analyses. Psychol Bull 2002, I28:3-72.

44. Bray JH, Adams GJ, Getz JG, Stovall T: Interactive effects of individuation, family factors and stress on adolescent alcohol use. Am J Orthopsychiatr 200 I, 71 :436-449.

45. Nash SG, McQueen A, Bray JH: Pathway to adolescent alcohol use: Family environment, peer influence, and parent expectations. J Adolesc Health 2005, 37:19-28.

\section{Pre-publication history}

The pre-publication history for this paper can be accessed here:

http://www.biomedcentral.com/1471-2458/9/172/pre pub
Publish with Bio Med Central and every scientist can read your work free of charge

"BioMed Central will be the most significant development for disseminating the results of biomedical research in our lifetime. "

Sir Paul Nurse, Cancer Research UK

Your research papers will be:

- available free of charge to the entire biomedical community

- peer reviewed and published immediately upon acceptance

- cited in PubMed and archived on PubMed Central

- yours - you keep the copyright

Submit your manuscript here:

http://www.biomedcentral.com/info/publishing_adv.asp
BioMedcentral 